\title{
Cultura del ilusionismo y ética de su práctica. Análisis de dos procedimientos cartomágicos
}

\author{
(1) Miguel Ángel Nigro \\ Universidad Nacional de las Artes, Departamento de Artes Visuales, Argentina \\ miguelnigro@fibertel.com.ar
}

Fecha de recepción: 13/01/2021. Fecha de aceptación: 29/03/2021

\begin{abstract}
Resumen
El presente trabajo es un registro de una de las etapas de la investigación en curso, centrada en el ilusionismo y la relación que éste mantiene con la dimensión material. El ilusionismo, como disciplina construida por la acumulación de conocimientos secretos, contempla tres componentes interdependientes: el contexto, el sujeto (ilusionista y espectador) y los objetos. En esta fase investigativa, me focalizo en los sujetos implicados, quienes modelan a través de su comportamiento, la morfología del campo artístico del ilusionismo. Considero oportuno analizar de qué manera y bajo qué condiciones se activa el intercambio de valores culturales en el interior de la comunidad mágica que, como artistas del entretenimiento, cumplen una clara función social. Este enfoque es apropiado para descubrir cómo se mueven los miembros implicados en el campo restringido, o sea en el seno de la hermandad de ilusionistas, y cómo se articulan con el público especializado y profano. Otros interrogantes se encadenan a este planteo como, por ejemplo, cuál es la naturaleza del trabajo, qué instituciones crean sus miembros (profesionales y aficionados) en un campo cuya deóntica se fundamenta en la ética del secreto y bajo qué valores humanos se vinculan, los cartómagos en particular, con el espectador-colaborador.
\end{abstract}

Palabras clave: ilusionismo, comunidad, trabajo, cartomagia, ética

\section{Culture of Illusionism and Ethics of its Practice. Analysis of Two Card Manipulation Procedures.}

\begin{abstract}
The present work is a record of one of the stages of an ongoing research project centered on illusionism and its relationship with the material dimension. Illusionism, as a discipline built by the accumulation of secret knowledge, contemplates three interdependent components: the context, the subject (illusionist and spectator) and objects. In this investigative phase, I focus on the subjects involved, who,
\end{abstract}


through their behavior, model the morphology of the artistic field of illusionism. I consider it appropriate to analyze in what way and under what conditions the exchange of cultural values is activated within the community of magicians that, as entertainment artists, fulfill a clear social function. This approach is appropriate to discover how the members involved in this restricted field -that is, within the brotherhood of illusionists- move and how they articulate with the specialized and profane public. Other questions are linked to this inquiry, such as what is the nature of work, what institutions create its members (professionals and amateurs) in a field whose deontics are based on the ethics of secrecy and under what human values are they connected -the card magician in particular- with the spectator-collaborator.

Key words: Illusionism, Community, Work, Card magic, Ethic

\section{Comunidad, miembros y trabajo en el campo del ilusionismo}

Toda actividad artística contiene un conocimiento teórico asociado a su práctica. Este plano epistemológico atiende tanto a las cualidades del conocimiento, así como a las relaciones que pueden establecerse con otros saberes y con los destinatarios.

Entre otros componentes la producción del arte comprende: la materia, los conceptos, los procesos, el contexto y los objetos resultantes. El conjunto de saberes teóricos y prácticos se plasma en un objeto o en un acontecimiento que posee cierto grado de espacialidad y temporalidad.

Las obras y los sujetos implicados en el arte se mueven en un espacio genérico de producción, circulación y reconocimiento. Es un espacio dinamizado por sus miembros, las instituciones y los intercambios, identificado con la categoría sociológica de campo. Un campo es un espacio social de acción y de influencia en el que confluyen vínculos sociales determinados, es una red de relaciones objetivas entre las posiciones que ocupan sus miembros. Según P. Bourdieu:

El campo es como un juego, pero que no ha sido inventado por nadie, que ha emergido poco a poco, de manera muy lenta. Este desarrollo histórico va acompañado por una acumulación de saberes, competencias, técnicas y procedimientos que lo hace relativamente irreversible. (2010:38)

El campo de las artes mágicas es un subgrupo, con relativa autonomía, del vasto campo de las artes escénicas, en el cual se incluyen las artes del entretenimiento. Según la clasificación kantiana, existen artes agradables discriminadas de las bellas artes. Larry Shiner especifica esta categorización: señalando que "los ejemplos que pone de las artes meramente agradables son: el narrar historias en una fiesta, una mesa bien puesta, o la música con ocasión de un banquete" (2004:209).En las "artes agradables", parecen estar comprendidas las teatralidades indeterminadas -juglería, animación, malabarismo, prestidigitación-, revaloradas en la actualidad como fuentes para nuevas formas espectaculares como la nueva magia, circo contemporáneo, cuenta-cuento, teatro para bebés.

El consenso social, reconociendo esta práctica como teatral, acuerda en adjudicarle a la magia la misión de entretener, animar o distraer. El dilema (pasatiempo o arte) se plantea por la amplia ocupación de espacios operativos que la especialidad abarca (fiestas, teatros, eventos sociales, programas televisivos, publicidad). La práctica se diversifica dentro de las posibilidades que ofrece la cultura definida como: 


\begin{abstract}
Un conjunto de ideas, si, más o menos articuladas, un patchwork más o menos bien tejido, pero también un repertorio de acciones con que se encuentra el participante de una escena a la hora de actuar, repertorio que se vincula con un conjunto de formas materiales y de instituciones que facilitan la exhibición y circulación de cierta clase de productos y que favorece un tipo de encuentro con los sujetos a los que están destinadas. (Laddaga, 2006: 22)
\end{abstract}

El ilusionismo creó una amplia oferta cultural, con productos bien definidos, con un destino social determinado. El vínculo humano entre ilusionista y público está codificado por la convención teatral y la convivencia entre pares está regulada por instituciones formales o acuerdos informales estables.

\title{
Comunidad
}

El ilusionismo posee un estatuto explícito cuyo primer mandamiento es no relevar secretos. A modo de preámbulo en casi todos los manuales de magia se encuentran advertencias como la siguiente:

¡NO REVELE LOS TRUCOS! Para bien de la magia y de usted mismo, nunca revele los trucos ni a sus amigos ni a sus parientes. Enseñar el secreto de una experiencia a quien no es aficionado a la prestidigitación, trae como resultado restarle méritos al artista y a la divulgación innecesaria entre el público del secreto, muchos de los cuales fueron celosamente guardados por siglos. iConserve la fama de hombre sobrenatural ¡NO REVELANDO LOS TRUCOS! (Mir, 1946: 3)

Para los magos, lo autorizado, lo prohibido y lo obligatorio, son los términos autoimpuestos que reivindican su autonomía y "su pretensión de producir y de imponer los principios de una legitimidad propiamente cultural, tanto en el orden de la producción como en el orden de la recepción" (Bourdieu. 2010: 38). La magia limita la libre circulación de sus saberes. Los miembros filiados en esta disciplina comparten en privado, sólo entre pares y con mucha discreción, el saber acumulado.

Los aspirantes acceden, de forma escalonada, a los valores de la práctica. El pacto al que adscriben, a través de su juramento, los hace depositarios de información privilegiada que la comunidad de magos les suministra. Podría pensarse que este vínculo se presta, dado su alto valor simbólico, a la mercantilización de secretos, pero el intercambio no funciona bajo esa mecánica. Es posible adquirir objetos trucados en el mercado, pero los secretos no se compran. La pedagogía del ilusionismo transmite, a cambio de una remuneración, juegos, trucos, procedimientos y valores, aunque la transferencia de lo más preciado, se produce por motivaciones bien distintas a las económicas. El apadrinamiento, el discipulado, la adopción, la familiaridad, son las metodologías afectivas que la magia construyó sobre el valor de la confianza.

Existen varios canales de formación como libros, revistas, material fílmico o tutoriales, pero la disciplina continúa fomentando el vínculo humano directo como medio más apto para revelar los secretos celosamente guardados. Un ilusionista recuerda, de su época de iniciado, que "el conocimiento más valioso -las obras maestras de verdad- se trasmitía en sesiones secretas y cónclaves ocultos. La del engaño, descubrí, es una de las pocas tradiciones orales que aún perviven" (Stone, 2014: 11). En este sentido, el ilusionismo mantiene viva una tradición semejante a la del gremio medieval en donde aún "no había artistas y artesanos, sino artesanos/artistas de variado rango y condición" (Shiner, 2004: 64). El ilusionismo es un reflejo de la antigua cofradía, esa comunidad productiva en la cual el aprendizaje se transmitía 
a través de la materialidad del oficio. La magia es depositaria de un patrimonio cultural transferido a través de la palabra reveladora y los objetos manipulables.

Todo producto artístico conserva algún nivel de información secreta, o al menos una noción envolvente de misterio a descifrar. Existen además enigmas técnicos de apariencias materiales bien visibles. Ciertas artes-oficios como la herrería o la alfarería, a causa de su técnica basada en el control del fuego, elemento de naturaleza inestable y de difícil manejo, se pueden homologar con la magia. En este sentido R. Mayrata, (escritor e historiador de la magia y el ilusionismo), destaca, citando a M. Eliade, el vínculo entre los oficios mencionados y la magia:

Aunque los poderes del herrero y alfarero son de un orden distinto, en las viejas culturas, en las más arcaicas, comparten con el chamán la condición de maestros del fuego. Mircea Eliade brinda una razón convincente. El alfarero modela formas nuevas en la arcilla con la intervención del fuego, al igual que el herrero moldea el hierro que el fuego convierte en flexible y dúctil. Lo que entraña que el fuego se declaraba -precisa Eliade- "como un medio de hacer las cosas más pronto, pero también servía para hacer algo distinto de lo que existía en la Naturaleza, y era, por consiguiente, la manifestación de una fuerza mágico-religiosa que podía modificar el mundo y, por tanto, no pertenecía a éste”. (2013)

En la misma dirección, Lèvi-Strauss realiza un estudio antropológico exhaustivo dedicado a la relación entre mito, psicología y alfarería en América, publicado en su libro La alfarera celosa. En lo referente a la sociedad de los alfareros dice:

En sociedades europeas tradicionales, el oficio de alfarero era preferentemente ejercido por un grupo y no tanto por un individuo aislado. Había familias de alfareros en que cada miembro -nunca mejor dicho- podía poner las manos en la masa. O bien un taller de alfareros, a veces un conjunto de talleres, elegía instalarse fuera de la aldea, en la proximidad de los bancos de arcilla necesarios a la industria. En estos casos, los alfareros formaban una pequeña sociedad distinta de la comunidad aldeana; pero no desempeñaban una función personalizada y bien caracterizada al interior de esa comunidad. (1986: 18)

La naturaleza del oficio del alfarero instaura un modo de organización comunitaria con sus propias reglas. Las comunidades interactúan con el resto de la sociedad de forma indirecta: "El alfarero llevaba sus productos al mercado, a la feria, o los confiaba a un intermediario. Las ocupaciones regulares y la vida cotidiana no le permitían establecer una relación directa con el resto de individuos" (Lèvi-Strauss, 1986: 18)

El producto del alfarero, como el del ilusionista, depende del estrecho contacto de la materia con sus manos. De forma coincidente con aquella la magia recrea juegos ilusorios introduciendo variantes subjetivas. La repetición de pases, movimientos o argumentos que auxilian al ilusionista, obedece a una matriz de repetición. Las formas que adoptan los juegos, que cada mago personalizó, obtenidas de manera parcial o total del acervo histórico, de su maestro o del saber acumulado (de celosa distribución), son el sello de identificación estilística.

La intimidad, el mutismo, los procedimientos heredados y la transferencia generacional, son características propias de la magia en cuanto a valores colectivos inmateriales que bien pueden equipararse a la alfarería. Sobre la instrucción del oficio Lèvi-Strauss agrega:

Otro observador apunta en el mismo sentido: “Cuando aprende a hacer alfarería, el niño imita tan rigurosamente a su instructor que su obra presentará las mismas 
particularidades [...]. Joven o viejo, el alfarero debe su estilo y su habilidad a la casa donde vive". Por esa razón, "el conocimiento de las técnicas cerámicas se considera un asunto privado. Sólo se habla de ellas en el seno de la familia". (1986:163)

Para la comunidad de ilusionistas las condiciones son semejantes. En el interior de la hermandad mágica los saberes circulan con cierta fluidez, pero son restringidos hacia el exterior. C. Dejours afirma, en una conferencia titulada Sufrimiento en el trabajo de 2016, que esta decisión debe ser reconocida y aceptada por medio de "un acuerdo normativo que va a ser la referencia para todo el grupo". Sin perder su función de entretenimiento social, el ilusionismo formuló, gracias a un conjunto de regulaciones, un oficio artístico.

Y cuando uno suma varios acuerdos normativos se construye lo que llamaremos una regla de trabajo. Una regla de trabajo es algo muy noble. Cuando tenemos varias reglas de trabajo articuladas entre sí, eso funda un oficio o una regla de oficio. Esa regla nunca tiene una vocación exclusivamente técnica o instrumental, al mismo tiempo y siempre, es una regla social que organiza la civilidad y el vivir juntos (Dejours, 2016).

Los magos se encuentran en entidades, círculos o asociaciones que fomentan actividades de intercambio. Cada una reglamenta la admisión y la conducta de sus miembros a través de un estatuto. El fortalecimiento de las asociaciones aumenta en sesiones periódicas -rituales casi sagrados-, que funcionan como espacios de sociabilización, desarrollo, negociación y formación.

Simon Aronson, prestigioso ilusionista norteamericano, señala en una entrevista, el valor de los encuentros: "la parte del secreto es lo realmente único en la magia. Confiamos el uno en el otro. Trabajamos, mostramos, engañamos, ayudamos a modificar los trucos de los demás". Con este pacto, los miembros "intercambian ideas, buscan consejo y constantemente tratan de engañarse mutuamente, sabiendo que sus colegas nunca revelarán secretos al público" (Huppke, 2003).

Los círculos no sólo funcionan como espacios de reunión, sino como focos de difusión de nuevas formas de pensar que "tiende a producirse por irradiación a partir de un centro, de forma muy similar a lo que ocurre con las lenguas y las culturas." (Stone, 2014: 35)

La comunidad, dentro de los alcances de la deóntica profesional, elabora conceptos y comparte valores estéticos, simbólicos y materiales, con una dinámica prevista por el campo:

Esos recursos colectivos, colectivamente acumulados, constituyen a la vez limitaciones y posibilidades. Al igual que un instrumento -un clavicordio o un piano-, cierto estado del campo artístico ofrece un teclado de posibilidades, pero cierra otras. No se puede hacer todo -cuartos de tono, por ejemplo-; tampoco se puede hacer cualquier cosa: hay cosas posibles, probables e imposibles; pensables e impensables. Hay sistemas de clasificación admitidos -por género, especialmente-, jerarquías que orientan las elecciones. (Bourdieu, 2010: 38)

Un ilusionista no puede conectar con el más allá, por ejemplo, pues no está dentro de los límites del campo, aunque, vale aclarar, que ciertas prácticas abusan de los secretos del ilusionismo para estafar y engañar. Se valen de técnicas, procedimientos o artefactos generados por el ilusionismo para activar otras expectativas. Los principios de la actividad, por permanecer incomunicados, se prestan a manipulaciones deshonestas y crean una suerte de contra-ética, que algunos magos -el más famoso fue Houdini-, se encargaron de denunciar. Los métodos del mentalismo -rama del 
ilusionismo que comprende demostraciones de poderes mentales, aparentemente extraordinarios o sobrenaturales- permiten dominar, de manera fraudulenta, entidades, energías o espíritus del más allá. Esta paradoja ética, de serias implicancias sociales, repercute a su vez en el núcleo del arte y es problematizado por los propios magos con reflexiones como esta:

Hace tiempo discutíamos el problema ético planteado en torno al mentalismo por la facilidad con la que el espectador acepta como reales los fenómenos paranormales que se le muestran y que el mago sabe que son falsos.

La actitud de provocar el efecto mágico para inmediatamente después “desilusionar" al espectador es ridícula: si el efecto no se produce no hay problema porque no hay magia, y si se produce ya no vale decir que no queríamos llegar tan lejos porque la transgresión ya se ha producido.

Con esto no quiero decir que lo que hay que hacer es engañar al espectador y convencerlo de que tenemos poderes paranormales. Eso tampoco es magia; solo es otra forma de ocultar el truco.

Pero no hemos dedicado nuestro mejor tiempo, nuestra soledad más íntima durante años y años para acabar detenidos por un problema tan absurdo que ni siquiera existe. (García, 2010)

La especificidad de la magia, contenida en su campo artístico, se desborda y se ubica en un umbral que satisface, por momentos de manera inadecuada, profundas preocupaciones humanas. Este corrimiento, junto a la fuga de secretos (a veces de forma ostentosa como el ciclo televisivo Mago Enmascarado, emitido por la cadena Fox Network entre 1997 y 98, expone deliberadamente los secretos mágicos), son dos anomalías que ponen a prueba el núcleo ético de la comunidad.

El ilusionismo, como singular disciplina para atesorar secretos, se descontrola con facilidad con procesos de masificación y deslocalización. Acciones desleales de naturaleza reveladora o desviadora, obligan a la comunidad mágica a reafirmar su legitimidad artística en relación con la sociedad a la que se dirige.

\section{Miembros profesionales y miembros aficionados}

Los saberes incluidos en esta zona espectacular son activados por los ilusionistas, repartidos en diversos rubros, estilos, subgrupos, categorías, personalidades o estéticas definidas. El límite del campo es difuso y sus componentes heterogéneos, pero el consenso general les atribuye a estos artistas un término genérico clasificatorio: magos. Un rasgo singular, en lo referente a la composición de agentes formadores del campo mágico, es la disparidad y mutabilidad de intereses artísticos y lucrativos.

De forma casi automática dos grandes conjuntos se diferencian en la disciplina: los profesionales y los aficionados. Los segundos suelen dominar numéricamente la actividad con el objeto de satisfacer su amateurismo. Ambos grupos se recortan con nitidez en el horizonte del campo y al mismo tiempo se solapan e intercalan con fluidez.

Los profesionales destinan toda su energía a crear un estatus reconocido a nivel local y global, ofreciendo el resultado de sus producciones, de forma directa, al mercado del entretenimiento. Perfeccionan habilidades, crean o adoptan curiosos pases, juegos o productos, y todas estas maniobras son objetivadas en sus actos escénicos. Aspiran a entrar en el círculo de notables de la magia. El ascenso es proporcional al volumen 
de trabajo y a la remuneración percibida. Suelen atender varios rubros de la práctica a la vez tales como formadores, actuantes, conferencistas o vendedores de artículos propios. Sus proyectos artísticos son modalidades que encajan a la perfección en una forma estandarizada de profesionalismo globalizado, son expresiones "individualizantes, más bien que colectivizantes, pero incluso cuando se dirigen a una colectividad suelen entenderla como si se encontrara ya constituida y se tratara simplemente de llevarla a la expresión" (Laddaga, 2006: 15). La tensión entre lo individual y lo colectivo suele ser ajena a la práctica del ilusionista. El profesional promedio es un productor individualista poco permeable a la creación comunitaria.

Su misión lo lleva a participar de acciones grupales solidarias que aporta distracción en situaciones críticas (catástrofes, hospitales, conflictos bélicos o comunidades vulnerables). Algunos ejemplos de redes que fomentan la cooperación y la ayuda son:

Red Maso de Magos Solidarios (Argentina), es "una entidad que tiene como misión ayudar con el arte de la magia e ilusionismo en Hospitales, Comedores y Escuelas Rurales, Entidades carenciadas y personas carenciadas, Ilevando el arte para ayudar" (Blog Red Maso, 1999)

Fundación de Magos Solidarios Abracadabra que "es una organización de acción social sin ánimo de lucro que trabaja en toda España” (Fundación Abracadabra, 2005)

Estos intentos de activismo solidario no transforman la base del sistema de la magia, que mantiene al artista y a su práctica, como agente unívoco, como figura espectacular que exige aislamiento.

La concreción de producciones societarias en la magia no "da lugar al despliegue de comunidades experimentales", como en otras prácticas artísticas, que a través de acciones voluntarias "pretende averiguar cosas más generales respecto a las condiciones de la vida social en el presente" (Laddaga, 2006: 15).

Los aficionados están movidos por una pasión dominante. Fomentan otros aspectos de la magia que la profesionalización suele olvidar: diversión, cooperación, pasión, investigación o mero entretenimiento. La del aficionado es una actividad agradable en sí misma, sin presión, sin obligaciones ni sufrimiento. La afición recupera el placer de la labor despreocupada en contacto con el estudio, los materiales y los procedimientos. La creatividad del aficionado produce novedades que no persiguen rentabilidad monetaria. Estas características no significan un descenso de calidad artística, todo lo contrario, colaboran en gran medida con la innovación y el progreso de la magia.

Estos miembros suelen producir teorías, metodologías y objetos, valorados y asimilados por los profesionales. Los aficionados iluminan fragmentos del campo con intensidad renovadora. Este grupo es propenso a responder a las urgencias sociales y comunitarias como acciones solidarias, educativas y de ayuda.

Los recursos que cada miembro ostenta, sea aficionado, principiante o profesional, cuyas funciones ejercidas dentro del campo artístico es amplia y variada -actores, animadores, constructores, productores, teóricos o comerciantes-, se evidencian y se ponen en tensión en los eventos esporádicos que la disciplina genera como competiciones, ferias, jornadas y congresos (el congreso más importante a nivel global es el organizado por el FISM, International Federation of Magic Societies y a nivel regional el organizado por FLASOMA, Federación Latinoamericana de Sociedades Mágicas). 
En este juego, la gente ocupa posiciones que están determinadas, en gran parte, por la importancia de su capital simbólico de reconocimiento, de notoriedad-capital distribuido desigualmente entre los diferentes artistas-. Hay, pues, una estructura de la distribución de ese capital que, a través de la posición que cada artista ocupa en esa estructura (la de dominante o dominado, etc.), determina $u$ orienta las estrategias de los diferentes artistas a través, especialmente, de la percepción que cada artista puede tener de su propio espacio. (Bourdieu, 2010: 39)

Es así como los ilusionistas se asocian, se ponen a prueba, se desafían, se acusan; en definitiva, una multiplicidad de situaciones especulativas se despliega en estos encuentros. La posición de aficionados y profesionales es puesta en crisis por los mismos miembros. Gabi Pareras, referente actual de la magia española, opina:

En magia es muy importante no hacer de la profesión una afición, ni tampoco de la afición una profesión. Que haya cobrado por hacerlo varias veces no significa que yo sea mago profesional. Es más, yo jamás me haría profesional, es una determinación que tomé hace ya muchos años. Entre otras cosas, limita la libertad de tener un repertorio propio, y también la libertad creativa. De un modo u otro te autoimpones unos códigos para ser comercial. (2007)

La reflexión identifica a la afición como instrumento de resistencia dentro del propio campo. Este rasgo de "distinción culturalmente pertinente" (Bourdieu, 2010: 93) es un marcador de la competencia simbólica que la ley del campo propone. Esta ley justifica también la "autoimposición de códigos comerciales" y la percepción que tienen de sí mismos los profesionales y aficionados.

\section{El trabajo}

El mago profesional se percibe como un artista-trabajador. Esta conciencia artística lucrativa lo ubica en una función determinada dirigida a grupos sociales y geográficos heterogéneos. El ilusionista promedio está entrenado para presentarse en un teatro convencional, para animar una celebración en una casa de familia ante un grupo reducido o para participar de megaeventos empresariales. Todas las actividades son realizadas a cambio de una remuneración. De cada estrategia laboral se desprenden ganancias acordes con la naturaleza del contratante. En la mayoría de los casos, son las dos últimas actividades (contrataciones particulares y empresariales) las que compensan a la primera (presentaciones teatrales), en especial, en Argentina.

La magia encontró una solución autosustentable, a diferencia de la actividad teatral que depende de una infraestructura financiera y productiva externa que gestiona el vínculo entre artista y público. El actor intenta movilizar al público para que acuda al teatro; en cambio, el mago busca un mercado para ofrecer sus servicios.

Cada evento exige un nivel de especificidad que obliga al mago profesional a flexibilizar sus procedimientos. Bodie Blake, mago profesional argentino con proyección internacional, ejemplifica en una entrevista realizada especialmente para esta investigación, las particularidades del servicio prestado por el ilusionista:

Yo trabajo con lo que yo pienso que puede ser útil (un objeto) para ese efecto que estoy creando. Ahora, si yo tengo un trabajo en una empresa, me llaman de un laboratorio, voy a tener que usar los elementos que necesito (artículos comerciales producidos por la empresa) para hacer ese tipo de magia ¡No puedo escapar! (Blake, 2020). 
La indicación final, "no puedo escapar", es atinente. Es una expresión coloquial interpretada como estar pendiente a las exigencias de un campo laboral dinámico donde la competencia es notoria.

Para dar respuesta a la demanda, en general dominadas por la urgencia, el ilusionista se enfrenta a lo que C. Dejours llama 'lo real en el trabajo', o sea, lo que se revela como resistencia al dominio técnico. Lo real, aquello que nos pone a prueba en un trabajo, es ante todo afectivo: sorpresa, molestia, desconcierto.

En el ejemplo citado, el objeto publicitado desafía lo procedimental y más que una resistencia, en sentido negativo, es un reto a la capacidad laboral y creativa del artista. Como artista-trabajador, el ilusionista se adapta con agilidad a las contingencias de la demanda y es consecuente con las condiciones contractuales: contexto social, características espaciales, mérito del servicio, objeto impuesto, ética profesional y validación del hecho estético. La entrevista arroja más datos sobre este tema:

Podés trabajar para una situación puntual, donde sabés que te contrataron para un lugar $X$. Sabés la condiciones que vas a tener en ese lugar $X$ y no podés modificar nada. Porque te contrataron para hacer algo en un lugar donde tenés 360 grados de público y no le podés decir al tipo (contratante), bueno vamos a poner un biombo acá. Te dice: ¡no!, [...] ¡ Lo que puedas hacer acá! sino ¡llamo a otro! (Blake, 2020)

Los repertorios artísticos son formateados a partir de la sensibilidad del mago y de la factibilidad de presentación. En el armado de actos mágicos la previsión más común es la posibilidad de sobre-adaptación a contextos disímiles. El ilusionista asume de forma pragmática la repartición política que la condición laboral propone:

ese tipo (el contratante) es más poderoso que vos, él tiene elementos y te está contratando, entonces tenés que hacer lo que él necesita. [...] Tenés que salir a buscar el objeto o el efecto que se adapte a esas condiciones" (Blake, 2020).

El servicio prestado por el mago intenta combinar con eficacia el juicio de utilidad y el juicio de belleza, que son, como señala Dejours, reconocimientos esperables en todo trabajo. El mago ajusta su inventiva a determinados encargos con una utilidad específica, reconocidos como productos artísticos. Este aspecto concreto convive también con la modalidad de trabajo abstracto. La magia trabaja en la elaboración de productos que no tienen un propósito específico más que la creatividad generalizada puesta al servicio del mercado.

La conducta, los miembros, los materiales, la comunidad, el trabajo, son los componentes principales que legitiman y modelan el campo cultural de la magia.

\section{Los coprotagonistas en la cartomagia}

El dato diferencial que presenta el ilusionismo, contrastado con otras teatralidades, es mantener al espectador en un estado hiper-atencional permanente. El receptor siempre está al acecho, a la espera de detectar un desliz que le ayude a comprender lo incomprensible. Inclusive, después del efecto, el espectador entusiasta, reconstruye la información obtenida para tratar de recordar cualquier detalle pasado por alto que pueda explicar el truco. El recuento de datos significativos siempre se hace a destiempo, como reza un axioma del ilusionismo: cuando ya es tarde. Sobre la base de esta convivencia la disciplina diseña sus juegos. 
La cartomagia, como categoría de magia de cerca, propone un vínculo humano estrecho y colaborativo. Quien haya cooperado en un juego de esta naturaleza, con seguridad quedó prendado a ciertas cavilaciones del tipo: ¿y si le hubiese nombrado otra carta? o ¡debí haber mezclado más a fondo la baraja! Una serie de especulaciones surgen a posteriori y evidencian la insuficiencia de la razón frente a la fascinación. Un enfrentamiento a corta distancia y en tiempo presente se da entre dos sujetos (cartómago y colaborador), y otro en la intimidad del colaborador, con posterioridad al prodigio, o sea en un tiempo y espacio distintos.

El destinatario desconoce que el cartómago y el proyectista del juego previeron un número bastante elevado de variables para asegurar el éxito mágico, pese a las mediaciones azarosas del espectador. El ilusionista procede por anticipación, el espectador por recapitulación.

Las competencias del destinatario se encuentran en franco desequilibrio con las del mago. En este escenario, el receptor tiende a sobreinterpretar las causas del fenómeno, adjudicándole al cartómago un poder superlativo. Por lo tanto "el intento de buscar un significado final e inaccesible conduce a la aceptación de una deriva o un deslizamiento interminable del sentido" (Eco, 1997: 43) que desemboca en un estado de sumisa admiración por parte del espectador.

La asimetría cognoscitiva es el instrumento por el cual se le adjudica al cartómago un estatus de superioridad espectacular. Desde una perspectiva antropológica y sociológica, también válida para el ilusionismo, Bourdieu advierte que:

En materia de magia -Mauss lo ha observado muy bien- la cuestión no es tanto saber cuáles con las propiedades específicas del mago, o incluso de las operaciones y las representaciones mágicas, sino determinar los fundamentos de la creencia colectiva o, mejor, del desconocimiento colectivo, colectivamente producido y mantenido, que subyace al origen del poder que el mago se apropia. (2010: 162)

Esta situación de privilegio, este "abuso de poder legítimo", es puesta siempre a prueba en el ilusionismo por la desconfianza de un receptor dispuesto a instalar una mirada radiográfica a todo lo que suceda.

La cartomagia, la magia de cerca en general, que se ocupa de las cosas insignificantes en tamaño y valor, es una práctica que se actualiza y valida con el acto cooperativo y precisa la tutela directa de al menos un espectador. Los objetos pequeños necesitan de un receptor multiplicador que oficie de garante del público alejado. Su posición, próxima al mago, lo convierte en la autoridad de control.

En estas demostraciones que se realizan en espacios reducidos, en general con la ayuda de una mesa, la proxemia es un dato ineludible para el análisis. Sentados o de pie, los cartómagos se ajustan a esta configuración espacial.

Con esta breve descripción, analizaré qué modelos básicos de convivencia teatral la especialidad alienta, y qué ética se genera con la colaboración del espectador cercano.

\section{Dos modelos de cooperación}

A través de la comparación -no valorativa sino procedimental- de dos artistas de la cartomagia, es posible registrar procesos de intercambio bien diferenciados que posicionan al receptor como sujeto pasivo, colaborativo o inclusivo. 
Para establecer relaciones, diferencias y semejanzas, es oportuno valerse de uno de los cartómagos argentino más reconocido a nivel global: René Lavand (Héctor René Lavandera.1928-2015), y contrastarlo con una figura actual como lo es el canadiense Shin Lim (Liang-Shun Lim.1991). Estas dos personalidades cartomágicas responden a un criterio de reconocimiento que abarca al menos dos registros:

Un registro de excelencia resultado de la admiración y reconocimiento invocados públicamente por un reducido grupo de entendidos, que suelen aplicar en sus valoraciones criterios específicos, y un registro "heterónomo", en el que se invocan criterios no específicos dotados de sentido en el mundo extra artístico. Dos criterios de justificación distintos en los que se basan las valoraciones de los especialistas y los profanos respectivamente. (Furió, 2003: 217)

Especialistas y profanos destacan a ambos artistas como notables en su arte. Los dos se definen como autodidactas. El primero a causa de su condición corporal (en un accidente perdió la mano derecha a temprana edad). Como Lavand era diestro, tuvo que crear singulares pases de manipulación para su mano izquierda: "no podía copiarle a nadie, tuve que crearme mis técnicas" (Lavand, 2014). El segundo se formó a través de tutoriales de YouTube y, al igual que Lavand, está condicionado físicamente por el síndrome del túnel carpiano, una afección bastante dolorosa que afecta a los dedos de la mano y el brazo. Los dos se especializan en magia de cerca, particularmente con naipes. Lavand solía añadir pocos y simples elementos a sus juegos (papeles, pocillo, navajas, billetera). La presentación de sus rutinas estaba estructurada sobre la base de un relato oral (anécdotas, poemas o cuentos breves) muy bien construido y apropiado para cada juego. La legitimación internacional de Lavand no necesitó de ningún título ganado en competencias consagratorias, como por ejemplo el mundial de magia organizado por el FISM (International Federation of Magic Societies). Participó de estos eventos sólo como invitado de honor, conferencista o figura principal. Lim, en cambio, produce un potente espectáculo visual y mágico asistido por materiales sintéticos y efectos especiales (cristales, acrílicos, humo). Los movimientos corporales y sus pases manuales en su acto sin palabras, están sincronizados a tempo musical (Lim se formó además como pianista). Su consagración la logró en los circuitos de alta competencia internacional con la obtención del primer premio en cartomagia en el Congreso FISM 2015. La producción de Shin Lim es una suerte de realidad aumentada que encaja a la perfección en los programas masivos de la industria del entretenimiento como el America's Got Talent (del cual también fue ganador de la edición 2018). Su prestigio se acelera con los beneficios que brindan la interactividad virtual y las redes sociales.

Para completar la reseña, destacaré que estos cartómagos apelan a los clásicos juegos de la cartomagia transformados y versionados. Uno de ellos es la carta firmada: una carta elegida al azar por un espectador es firmada por éste y perdida en el centro de la baraja; la carta desaparece de su ubicación y reaparece en lugares imposibles: billetera del mago, bolsillos, sobres lacrados, entre otras soluciones.

René Lavand y Shin Lim provocan con este clásico un efecto impactante con estrategias diferentes. El elemento de relevancia para el análisis es la situación en la que es puesto el espectador que colabora con el juego.

Lavand presentaba la rutina con las características de magia de impromptu (especialidad del ilusionismo que comprende a todos aquellos juegos que pueden ser presentados en cualquier momento y lugar con objetos cotidianos disponibles). Introducía la escena contando, de pie, frente a la mesa, un cuento que no está vinculado al juego. Al final del relato suele justificarse con una frase amigable: "Les cuento esto porque me gusta contarles historias". Esta suerte de preámbulo es un elemento que caracteriza su estilo: 
Su manera de contar, su personalidad, su estilo, lo hacen inimitable, único. En su estilo está la narración, pero también la actuación y la dirección. Él sabe en qué momento pararse, cómo y qué movimiento de baraja debe combinar con qué palabra. (Landini, 2016: 72)

Sentado con dos colaboradores del público a cada lado, a los que llama por su nombre, Lavand dialoga con respetuosa autoridad. La situación, casi familiar, es potenciada por la invitación del cartómago a participar de un "divertimento, nada más", con "unas pocas cartas para ser más objetivo". Pide con amabilidad a uno de los colaboradores la selección y rubrica de una carta, agregando "me llevaré esa firma de recuerdo". Siempre consciente de sus destinatarios próximos, lejanos y remotos, Lavand esclarece cada detalle, incluso para las cámaras de video. La carta perdida por sucesivos cortes de la baraja siempre reaparece en la misma posición del mazo. Tal procedimiento le permite escenificar un falso sinceramiento del truco: "yo corto y monto correctamente (mientras lo realiza), pero ni corto ni monto (descubriendo la carta firmada siempre como última carta del mazo)". El desarrollo del juego va creciendo con condiciones más adversas. Todas las manipulaciones son realizadas de manera pausada y sin arrebatos espectaculares.

Lavand desarrolló un pensamiento estético y ético condensado en la frase: "No se puede hacer más lento". En el núcleo de esta afirmación descansa la complicidad de la Misdirection: "Arte de atraer la atención de las personas hacia una posición o lugar particular, siendo normalmente un punto sin importancia con respecto a la idea central. Esto se debe a que la idea central contiene algún punto secreto que quiere obviarse a los ojos del público" (Roll, 2016). En una de sus conferencias para TED Tandil, Lavand explicaba:

La palabra prestidigitación no tiene vigencia, nunca la tuvo. Son otras las técnicas a emplear. No la velocidad, de ninguna manera. La postura, la palabra, los ángulos, su majestad: la Misdirection. En el lenguaje militar divertir es hacer creer que uno entra por aquí cuando entra por el otro lado ¡Claro! Pero no la velocidad. (2014)

La palabra que especifica su técnica es: lentidigitación, o sea, prestidigitación en cámara lenta. Por un lado, la lentidigitación contradice la técnica precedente y, por otro, quizás lo más importante, es un canal de integración más confiable para el receptor. Desde este aspecto técnico hasta la introducción de frases diseñadas como: "que linda blusa tiene usted, muy elegante", "me van aplaudir si sale" o "ustedes me hacen sentir como uno más" -que parecen improvisadas-, Lavand horizontaliza la convivencia con sus destinatarios.

Para el climax final de la carta firmada, Lavand entrega el mazo a un colaborador para ser mezclado, en esta instancia suele valorar su intervención: "usted lo hace muy bien". Terminada la mezcla, pide al espectador que diga una posición: "seré curioso, ¿qué lugar prefiere, primera, segunda, tercera?". Cualquiera sea el número elegido la carta firmada es revelada en la posición deseada, acompañada por una anécdota personal, de carácter moralizante, que se articula de manera precisa con sus movimientos.

La colaboración de un representante de la audiencia que presta una ayuda explícita es, en la escena creada por Lavand, un intercambio interpersonal. El invitado para elegir un naipe, mezclar y cortar la baraja o mostrar el naipe al resto de la platea, se transforma, a partir de ese señalamiento, en coprotagonista del juego. La inclusión de los sujetos no es meramente instrumental. La convivencia transitoria es un componente constructivista de la escena. La simpleza de Lavand persuade al espectador y juntos construyen un sistema participativo en continuo cambio y progresión.

Shin Lim presenta su versión de la carta firmada con total espectacularidad cumpliendo los requisitos del show televisivo masificado America's Got Talent 2018. La mesa, los naipes y otros accesorios son los objetos de la escena. Shin Lim, que permanece 
siempre parado detrás de la mesa, invita a una colaboradora para que se siente a su derecha. Lim solo le habla a ella para instruirla sobre ciertas acciones que debe cumplir: elegir una carta, firmarla, sujetarla entre sus manos y poco más. La participación de la espectadora (concertada en este caso) tiene una función de sostener la espectacularidad del cartómago. Es la intermediaria, a través de expresiones de asombro, entre la mesa y la teleaudiencia.

La carta firmada, entre otros viajes inexplicables, se traslada mágicamente del mazo normal a un sobre lacrado. Luego viaja a un mazo de naipes transparentes que se solidifican en un bloque acrílico, mientras sale humo, entre las manos de la colaboradora. Una serie de golpes de efectos visuales constituye la clave de la rutina que el cartómago realiza dosificando movimientos lentos con cambios repentinos. La asepsia de la escena, dominada por la luz azul de fondo, está reforzada por la transparencia de la materialidad.

Como demuestran los ejemplos, la cartomagia instituye la figura de colaborador ajeno. El espectador invitado para ayudar en la escena, se transforma, a partir de ese señalamiento, en coprotagonista del evento.

La invitación de Lavand a participar no da lugar a la duda o a la desconfianza. El vínculo humano es el elemento constitutivo y "deja en su filosofía bien claro que no debe ser el espectador quien desafíe al cartómago. El espectador sólo debe disfrutar de lo que está mirando, sorprenderse y, fundamentalmente, emocionarse" (Landini, 2016: 74). La figura de tahúr recuperado, alimentada por el propio Lavand en sus narraciones, crea una atmósfera didáctica y moralizante. Traslada -en apariencia- al ámbito del divertimento, un comportamiento social inadecuado: la estafa. Sus relatos parecen oscilar entre lo dramatúrgico y la confesión íntima de un pasado oscuro. A pesar de que todos sus argumentos son ficticios, creados en colaboración con guionistas, el público profano tiende a creer estas historias y atribuye un alto grado de verosimilitud a las vivencias del cartómago. Lavand apela, con este procedimiento, a una identificación que excede lo teatral.

A partir de cosas simples, Lavand se acerca a su público con un objetivo preciso: "En mi caso, el adminículo es la baraja; es mi medio de comunicación humana y artística para lograr el fin: emocionar" (2003: 51). Lavand intercalada en sus actos, con sensibilidad escénica, la participación activa del sujeto. Resulta de esta actuación una experiencia teatral compartida e inclusiva.

Shin Lim produce otro tipo de emociones enmarcadas en la cultura de la hiper-visualidad. La inmediatez de los efectos deja en el espectador una huella instantánea. Raudos y espectaculares movimientos, precedidos por una lenta preparación, resuelven los finales de cada etapa del juego. Lo mágico se produce por una serie incomprensible de efectos encadenados: la carta firmada se borra de la cara del naipe, se transfiere a un tatuaje en el pecho del cartómago y reaparece entre sus labios, se reimprime desde las manos de la invitada a un naipe de cara blanca. Estos son sólo los efectos iniciales que prometen efectos superadores, como así resulta.

El estilo de Lim reposado y autosuficiente transmite autoridad y superioridad. El tratamiento del componente humano, reflejado en el vínculo con la colaboradora, responde a una necesidad amplificadora. Lim se apoya en su invitada, desbordada por el asombro, la cual no intercambia, a diferencia de Lavand, valores de otra índole humana más que los estrictamente espectaculares. La participación del público se reduce a lo indispensable: asegurar, en el inicio, el principio del azar a través de la elección y la firma del naipe. El resto de su participación es pura admiración. La figura de Shin Lim tanto a nivel artístico como empresarial, es un ejemplo de modelo global hegemónico que funciona como faro para muchos iniciados. Define una teatralidad 
distanciada y una matriz profesional corporativa. El componente de exclusividad de su personalidad es notorio, como se advierte en su página web: "SHIN LIM DOES NOT answer. The team management will reply" o "We only accept Corporate Level Events \& Parties" [SHIN LIM NO responde. La dirección del equipo responderá. Solo aceptamos eventos y fiestas a nivel corporativo].

En la estética de cada cartómago tratado subyace una política espectacular que transforma al espectador en un elemento expresivo. En el caso de Lavand, lo convierte en lo que Tamariz denomina: "especta-actor" (2016: 18), mientras que para Lim es un espejo multiplicador del asombro.

En definitiva, la cartomagia es un arte generador de convivencia, de encuentro animado, y esta preocupación humana está en el centro de la disciplina. En una conferencia de 1975, Alex Elmsley, destacado cartómago inglés, sintetiza la función del artista en comunión con sus destinatarios:

La razón más común para que alguien se aburra, es que dicha persona sienta que no tiene influencia en lo que está ocurriendo en dicho momento, o sea, que está siendo ignorada o dejada de lado. Esto que acabas de leer también puede aplicarse a la forma en que muchos magos hacen sus sesiones de Magia. Ellos ignoran al público, y parece que hacen los juegos para ellos mismos. (Minch, 1979: 18)

\section{Conclusión}

El campo del ilusionismo, movilizado por una comunidad de pares celosa de los principios de su arte, se orienta a crear formas estéticas, valores simbólicos, productos para la industria del entretenimiento y, sobre todo, modelos de interacción con sus destinatarios. La creación de instituciones propias, poco comunicadas con la institucionalidad pública, preserva la cultura del secreto en un ámbito reservado. Su permanencia se respalda en la antigua tradición pedagógica de la transmisión exclusiva y personalizada, al mismo tiempo que se hace cargo del exceso productivo de la contemporaneidad: tecnologías, espacios, acontecimientos y redes comunicacionales.

Los artistas integrados en esta cultura, identificados en dos grupos básicos bien articulados (profesionales y aficionados), resumen aspectos ocupacionales concretos: el trabajo remunerado y la labor vocacional. Los primeros son propensos a reestructurarse por las fuerzas sociales y por la industria del entretenimiento; los segundos mantienen una actitud refractaria o indiferente a la dinámica del mercado. La división de roles no es privativa de la magia; otras expresiones artísticas presentan iguales condiciones, pero la interdependencia y la negociación simbólica constante entre ambos grupos es un rasgo constitutivo del campo mágico.

La diferencia procedimental, en los dos casos comparados, otorga ejemplos de las distintas formas dialécticas que se generan en el vínculo entre artista (cartómago) y receptor (colaborador). La oscilación entre la coparticipación y la simple expectación cercana demuestra que el arte de la cartomagia, destinada en primer lugar a entretener, es una escena social propicia para analizar modelos de convivencia. La relación recíproca e inmediata que ofrece la magia de cerca es una oportunidad para repensar el contrato humano particularizado en la teatralidad.

El producto de cada artista otorga un modelo ético capaz de afectar a los miembros, a la comunidad mágica y al grupo social al cual se dirige. La relación subjetiva en la cartomagia no es un hecho pasivo, es un elemento constitutivo y activo que puede influenciar de manera individual y colectiva, reforzando o transformando situaciones y valores. 


\section{Dibliografía}

»Bourdieu, P. (2014). Versión castellana: El sentido social del gusto. Elementos para una sociología de la cultura. [Trad: Alicia Beatriz Gutiérrez]. Buenos Aires: Siglo XXI

» Eco, U. (1997). Interpretation and Overinterpretation. Versión castellana: Interpretación y sobreinterpretación. [Trad: Juan Gabriel López Guix]. Madrid: Cambridge University Press

» Furió, V. (2003). “¿Clásicos del arte? Sobre la reputación póstuma de los artistas de la época moderna". Matèria Revista Internacional d'Art. $N^{\circ}$ 3. Universitat de Barcelona https://revistes.ub.edu/index.php/materia/article/view/11542 - Visto el $15 / 5 / 2020$

»Laddaga, R. (2006). Estética de la emergencia. La formación de otra cultura de las artes. Buenos Aires: Adriana Hidalgo

»Landini, M. B. (2016). “Magia, narraciones, actuación en René Lavand, dramaturgo". En Musitano Adriana (comp.) Actas de las VIII Jornadas Nacionales y III Jornadas Latinoamericanas de Investigación y Crítica Teatral (pp.72-8o). Buenos Aires: AINCRIT. https://drive.google.com/file/d/oB_tISAR5St_dbk11VGltZ$\mathrm{mE}_{3} \mathrm{~d}_{3}$ 16UGQ 4 dUMyNFYycFFhNoN3/view . Visto el 22/10/2018

» Lavand, R. (2003). La belleza del asombro. Madrid: Páginas Libros de Magia

» Lévi-Strauss, C. (1986). La alfarera celosa. [La potière jalouse. Trad. Caterina Molina]. Barcelona. Paidós Ibérica.

»Mayrata, R. (2013). El hombre incombustible, Lionetto y los saludadores. https:// www.fronterad.com/el-hombre-incombustible-lionetto-y-los-saludadores/ Visto el $13 / 6 / 202$

»Minch, S. (1994). Obras completas de Alex Elmsley, Vol 2. [Collected Works of Alex Elmsley, Vol. 2. Trad: Javier Piñeiro Tuero]. Madrid: Páginas Libros de Magia

» Mir, A. (1946). Trucos Famosos. Magia Prestidigitación e llusionismo №11. Buenos Aires: Catalogo Palacio Magia Moderna

"Shiner, L. (2004). La invención del arte. Una historia cultural. [The Invention of Art. A Cultural History. Trad. Eduardo Hyde y Elisenda Julibert]. Barcelona: Paidós Ibérica.

"Stone, A. (2014). Engañar a Houdini, magos, mentalistas, ilusionistas y los poderes ocultos de la mente. [Fooling Houdini, magicians, mentalists, math geeks, and the hidden powers of the mind. Trad. María Serrano]. Barcelona: Debate.

» Tamariz, J. (2016). El arco iris mágico. Madrid: Gema Navarro.

\section{Fuentes}

" Abracadabra Fundación. https://fundacionabracadabra.org/es/Visto el $15 / 1 / 2020$

》Blake, B. (2020). Entrevista inédita. Realizada el 12/2/2020

"Dejours, C. (2016). Conferencia: Sufrimiento en el trabajo. UNAM: México https://www.youtube.com/watch?v=yBR7247jrKE Visto el 1/3/2020 
»FISM. https://fism.org/championship-contests/contest-rules/ Visto el $27 / 02 / 2020$

"FLASOMA. https://www.flasoma.org/ Visto el 25/02/2020

"García, L. (2010). La decisión de hacer Magia I. Tertulias Mágicas Granadinas http://tertuliasmagicasgranadinas.blogspot.com/2010/12/la-decision-de-hacer-magia-i-luis.html?m=1 Visto el 18/1/2020

" Huppke, R. W. (2003). Illusionist Icon Still Has Trick Up Sleeve. Chicago Tribune, http://www.simonaronson.com/about.html Visto el 24/3/2020

» Magicpedia. https://geniimagazine.com/wiki/index.php?title=Val_Valentino Visto el 18/03/2020

"Lavand, R. (2013). Ambitious Card https://www.youtube.com/ watch?v=rh7NTWxOo3Y Visto el 24/2/2020

» Lim, S. (2018). Best Close up Card Magic America's Got Talent 2018 Auditions - 13 Episode https://www.youtube.com/watch?v=VXuqGHBD2G 4 Visto el 27/2/2020

»Lim, S. https://www.shinlimmagic.com/ Visto el 24/5/2020

»Pareras, G. (2007). Entrevista http://www.magiapotagia.com/archive/index.php/ t-8058.htm Visto el 13/4/2020

»Red Maso http://reddemagossolidarios.blogspot.com/ Visto el 10/1/2020

» Roll, D. (2016). ¿Qué es la misdirection? https://davidrollcienciapolitica.com/ que-es-misdirection/ Visto el 10/4/2020

» Romhany, P. (2015). Shin Lim, Su camino hacia el éxito https://dobledorso.com/ shin-lim-su-camino-hacia-el-exito/Visto el 29/5/2020

» TEDx Tandil 2014. http://www.tedxtandil.org/\#oradores Visto el 15/5/2020 